\title{
Numerical verification of composite rods theory on multi-story buildings analysis
}

\author{
Alaa El-Din Mansour ${ }^{1,}{ }^{*}$, Vladimir Filatov ${ }^{1}$, Michael Gandzhuntsev ${ }^{1}$ and Nikita Ryasny ${ }^{1}$ \\ ${ }^{1}$ Moscow State University of Civil Engineering, Yaroslavskoe shosse, 26, Moscow, 129337, Russia
}

\begin{abstract}
In the article, a verification proposal of the composite rods theory on the structural analysis of skeletons for high-rise buildings. A testing design model been formed on which horizontal elements been represented by a multilayer cantilever beam operates on transverse bending on which slabs are connected with a moment-non-transferring connections and a multilayer columns represents the vertical elements. Those connections are sufficiently enough to form a shearing action can be approximated by a certain shear forces function, the thing which significantly reduces the overall static indeterminacy degree of the structural model. A system of differential equations describe the operation mechanism of the multilayer rods that solved using the numerical approach of successive approximations method. The proposed methodology to be used while preliminary calculations for the sake of determining the rigidity characteristics of the structure; are needed. In addition, for a qualitative assessment of the results obtained by other methods when performing calculations with the verification aims.
\end{abstract}

\section{Introduction}

Nowadays, the most common and demanded structures analysis and calculation method is the finite element method. In parallel, other methods (both numerical and numericanalytical) are also under development. Further development and improvement of design methods is mainly carrying out to ensure the reliability of design decisions, especially when studying unique buildings and structures.

One of the methods are mainly functioned to analyses multi-story skeletons through calculating the configuring elements with the aid of Composite Rods Theory [1] (for its improver $\uparrow$ A.R. Rzhanitsyn). One of those who first applied this was P.F. Drozdov [2]. Further later; the theory of composite rods was also functioned to calculate building frames for seismic actions [3].

$†$ Alexey Rufovich Rzhanitsyn (1911 - 1987) born to a family of a Latin language teacher in one of Moscow high schools. After graduation, worked for some time in manufacturing. Then, studied at Moscow construction research institute (MICI) [Now; Moscow State University of Civil Engineering (MGSU)], which he graduated in 1936, and work in the Central Research Institute of the Construction Materials Industry. In 1945, Rzhanitsyn defended his doctoral dissertation thesis while in 1952, became the head of the materials strength laboratory at the central research institute where he worked. In parallel, taught at the MICI, where in 1972 been promoted to be a professor at structural mechanics department.

*Corresponding author: alaa_for_all@hotmail.com 
Reinforced concrete structures [4-6], perforated steel beams [7, 8] and structures made of timber $[9,10]$.

In such an approach, the calculation design model of the structure is imposed as multilayer composite cantilever beams, where layers are acting as vertical supporting structural elements. Slabs act as elastic diaphragms with neglected local deformation. Thus, those individual beams are absolute rigidly connected by cross-links and elastic shear bonds. Due to such rigid linking, the resulting system is equivalent to $(n+1)$ joining bars along the same bending axis (Fig. 1), where (n) is the number of joints.

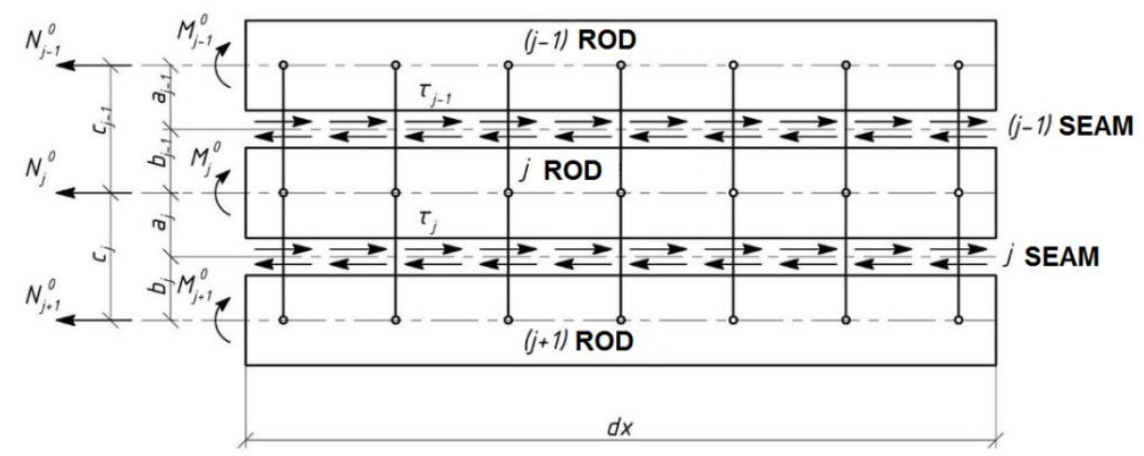

Fig. 1. Rigid linking in between individual beams.

When the composite rod is deformed, shearing forces arise in the shear connections of each connecting point. In order to simplify the model, discrete connections are replaced by a shearing forces function on seam per unit length as shown above. The stress-strain state of a compound rod is generally determined by solving a system of $(\boldsymbol{n}+2)$ differential equations of the $2^{\text {nd }}$ degree.

Below, A numerical calculation technique for a rod consisting of two identical end $\quad(n$ $=1)$.

\section{Calculation Methodology}

The differential equations system of solution take its dimension-less form through

$$
\begin{gathered}
\frac{d^{2} m}{d \psi^{2}}=-p ; \\
\frac{d^{2} w}{d \psi^{2}}=-\frac{1}{2}(m-\tilde{t}) ; \\
\frac{d^{2} \tilde{t}}{d \psi^{2}}=-k(m-s \tilde{t}),
\end{gathered}
$$

Where

$$
\psi=\frac{x}{l} ; \tilde{t}=T \frac{c l}{E I} ; m=M \frac{l}{E I} ; w=\frac{y}{l} ; p=\frac{q l^{3}}{E I} ; s=\frac{4 I}{F c^{2}}+1 ; k=\frac{\xi}{2} \cdot \frac{c^{2} l^{2}}{E I}
$$

$\mathbf{x}$ - Is the coordinate measured along the axis of the composite rod; E, I, F - modulus of elasticity, moment of inertia, cross-sectional area of a single end of the composite rod respectively; $\mathbf{q}$ - A distributed load intensity; $\mathbf{M}$ - The total bending moment over the section of the composite rod devoid of shear connection from the action of the external load; $\mathbf{T}$ - shear forces accumulated along the length of the rod from its origin to the section under consideration; $\mathbf{l}$ - span of the rod; $\mathbf{y}$ - deflections of the 
composite rod (identical for each end due to the absolute rigidity of the cross-links); $\mathbf{c}$ - the axial distance between rod sides; $\xi$ - the shear stiffness of the seam.

When solving the above shown system of differential equations, boundary conditions given in [11] should be considered As per (Fig .2), In the case of free shear by the end of a composite rod In both cases: with the hinged support of the composite beam, at a free edge; at a rigidly embedded edge, where, ( $\varphi$-friction coefficient) are specified, in particular, straining actions (bending moment $\&$ transverse force), deformations [draft (slippage) \& rotation] a zero values.
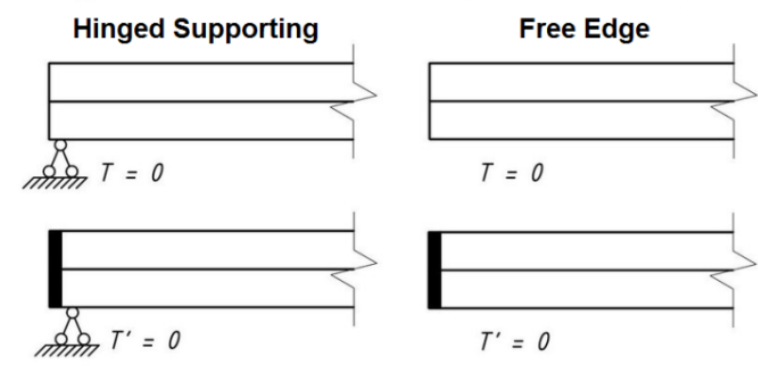

\section{Fixed Supporting}

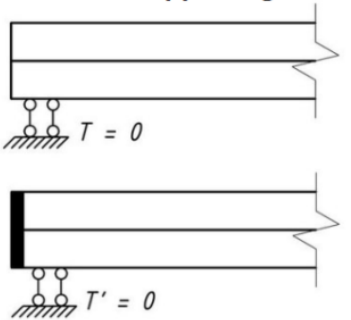

Fig. 2. Different boundary conditions.

So that to solve the differential equations system of EQ.(1), EQ.(2) \& EQ.(3), the successive approximations method (MPA) developed in [11]. This method has high accuracy specially when considering the finite continuity of applied function, its first and second derivatives, and discontinuities of the right-hand sides of the differential equations without resorting to the use of generalized functions. The MPA was early successfully verified on plates, shells calculation on both rigid supports and elastic foundations. Also, on compressedcurved monolithic beams subjected to static linear \& nonlinear actions, dynamic loads and on stability [11].

Now, the difference equation of MPA approximating EQ.(1) on a uniform mesh with step $\mathrm{h}$ at a regular point

$$
\begin{gathered}
m_{i-1}^{R}-2 m_{i}^{L}+m_{i+1}^{L}+\Delta m_{i}+h \cdot \Delta m_{i}^{\prime}= \\
=-\frac{1}{12} h^{2}\left(p_{i-1}^{R}+10 p_{i}^{L}+p_{i+1}^{L}\right)+\frac{5}{12} h^{2} \cdot \Delta p_{i}+\frac{1}{12} h^{3} \cdot \Delta p_{i}^{\prime},
\end{gathered}
$$

Where $\Delta m_{j}={ }^{L} m_{j}-{ }^{R} m_{j} ; \Delta m_{j}^{\prime}={ }^{L} m_{j}^{\prime}-{ }^{R} m_{j}^{\prime} ;{ }^{L} m_{j}^{\prime}=m_{j-0}^{\prime} ;{ }^{R} m_{j}^{\prime}=m_{j+0}^{\prime}$; $m^{\prime}=\frac{d m}{d \psi}$; The remaining quantities of this type have a similar meaning. Approximation

(1) at the left boundary node

$$
h m_{i}^{\prime}+m_{i}-m_{i+1}=\frac{1}{12} h^{2}\left(h p_{i}^{\prime}+5 p_{i}+p_{i+1}\right)
$$

The difference approximation of both EQ.(2) \& EQ.(3) can be performed by analogy also with the use of [11]. The resulting difference equations to be written successively for all calculation nodes of the model.

\section{Numerical example}


To illustrate the previous explained methodology, down here calculation results of a multistory reinforced concrete frame that shown in (Fig. 3) on four different proposals, is presented

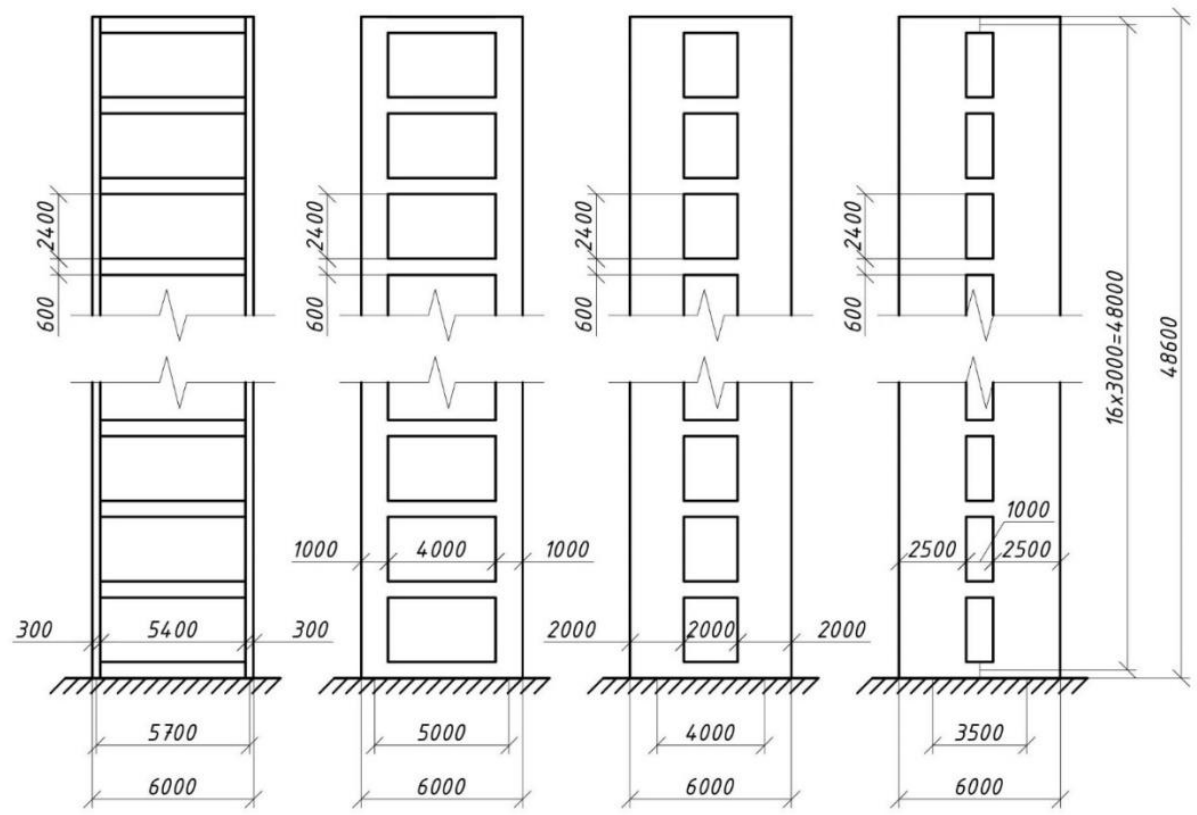

Fig. 3. A multi-story frame with its different proposals.

\section{Initial Data}

Modulus of elasticity of reinforced concrete $\mathrm{E}=\underline{32.5} \cdot 10^{3} \mathrm{MPa}$; the structural initial thickness is $300 \mathrm{~mm}$, the remaining geometric dimensions in millimeters are shown in (Fig. 3); four versions of the frame under study different from each only in the width of vertical structural elements such as 300,1000, 2000 and $2500 \mathrm{~mm}$. respectively with a distributed load of intensity $\mathrm{q}=1 \mathrm{kN} / \mathrm{m}$ is applied over the entire height from one side of the frame.

The shear seam stiffness is determined from [12] as

$$
\xi=\frac{24 E}{B c^{2}\left(\frac{2 C}{I_{\Pi}}+\frac{B}{I_{\mathrm{B}}}\right)},
$$

Where $I_{R}$ - the horizontal bridges moment of inertia (horizontal elements); $I_{\mathrm{B}}$ - the (vertical elements) moment of inertia; $\mathrm{B}$ - axial dimension in between bridges (height of the floor is $3000 \mathrm{~mm}$ ).

\section{Results}

Table 1 shows the values of horizontal displacements (drifts) at 48 meters for four different calculations by the theory of composite rods and in parallel via LIRA-CAD (LIRA-SAPR) program that based on finite element method (FEM).

The finite element results were obtained using elements modeled as normal (usual nonspecial) frame elements.

For the aim of solution convergence evaluation using composite rods theory, several numerical resulting values been carried out on bases of meshes different in dimensions by 
dividing the rod along the length by 4 segments $\left(h_{1}=1 / 4\right)$, by 8 segments $\left(h_{2}=1 / 8\right)$, by 16 segments $\left(h_{3}=1 / 16\right)$, by 32 segments $(h=1 / 32)$ and by 256 segments as well.

Table 1. Horizontal frames drifting at elev. 48 meter from base on $\mathrm{mm}$

\begin{tabular}{|c|c|c|c|c|c|c|}
\hline \multirow{2}{*}{$\begin{array}{c}\text { Calculated } \\
\text { Solution No. }\end{array}$} & \multicolumn{5}{|c|}{ Numerical solution using Composite Rods Theory } & $\begin{array}{c}\text { FEM solution (usual } \\
\text { frame elemental } \\
\text { model) }\end{array}$ \\
\hline 1 & 39.81 & $\mathrm{~h}=1 / 8$ & $\mathrm{~h}=1 / 16$ & $\mathrm{~h}=1 / 32$ & $\mathrm{~h}=1 / 256$ & 42.34 \\
\hline 2 & 12.55 & 12.71 & 12.73 & 12.73 & 12.74 & 12.72 \\
\hline 3 & 7.94 & 7.96 & 7.96 & 7.96 & 7.96 & 7.91 \\
\hline 4 & 6.57 & 6.58 & 6.58 & 6.58 & 6.58 & 6.53 \\
\hline
\end{tabular}

For calculated solutions (2), (3) \& (4), an additional fineness been added to computations by FEM via using additive shell elements sized $(100 \times 100) \mathrm{mm}$ that resulted out with values shown down in Table 2

Table 2. Horizontal frames drifting at elev. 48 meter from base on $\mathrm{mm}$

\begin{tabular}{|c|c|c|c|}
\hline Calculated Solution No. & $\begin{array}{c}\text { Composite Rods } \\
\text { Theory }\end{array}$ & $\begin{array}{c}\text { FEM solution (frame } \\
\text { elements model) }\end{array}$ & $\begin{array}{c}\text { FEM solution (shell } \\
\text { elements model) }\end{array}$ \\
\hline 2 & 12.73 & 12.72 & 10.97 \\
\hline 3 & 7.96 & 7.91 & 5.33 \\
\hline 4 & 6.58 & 6.53 & 4.34 \\
\hline
\end{tabular}

\section{Conclusions}

The demonstrated theory shows an effective numerical approach for calculating composite rods which accuracy is high and converges the solutions rapidly considering discontinuous load functions.

This technique extremely suits the calculation of structures that lead to the composite rod models: brace-less trusses, Virendel girders [12], perforated beams and skeletons of high-rise buildings.it also suits those structures that behavior simulate rod structures.in such cases, Composite rods theory always give satisfying results on various sparse grids (with a small number of breakdowns of the structure along its length into the calculated sections) and as usual, so that we can obtain the required parameters (forces, displacements) at any point on a cross section, this point should be a node of the computational mesh. The technique procedure for determining forces in a section of a composite rod we described in details in [13]. Finally, when it is desired to calculate skeletons of multi-story buildings with considerable cross sections and rigid shear walls, the proposed method can just be used to perform preliminary or estimation calculations.

\section{References}

1. A.R. Rzhanitsin. Composite rods and plates. Moscow: Stroiizdat, 316 p. (1986)

2. P.F. Drozdov, M.I. Dodonov, L.L. Panshin, R.L. Surukhanyan. Designing and calculation multi-storey civil buildings and their elements. Moscow: Stroiizdat, $351 \mathrm{p}$. (1986)

3. A.N. Kuleshov. Bulletin of the Adyghe State University. Series 4: Naturalmathematical and technical sciences, 4, pp. 148-154. (2008)

4. K.Z. Bashirov ACADEMIA. Architecture and construction, 2, p.125-128. (2013)

5. V.S. Fedorov, K.Z. Bashirov, V.I. Kolchunov. ACADEMIA. Architecture and construction, 2, p.116-118. (2014) 
6. R.F. Fardiev, A.K. Ashrapov, Kazan State University of Architecture and Civil Engineering, 4, pp. 363-369. (2015)

7. A.I. Pritykin, News of Institutions of Higher Education. Construction, 10, pp. 110-116. (2009)

8. A.I. Pritykin, Bulletin of MGSU, 4, pp. 177-181. (2009)

9. V.I. Linkov, Construction mechanics and calculation of structures, 5. pp. 30-35. (2011)

10. Y.V. Krasnoschekov, Bulletin of the Siberian State Automobile and Highway Academy, 14. pp.28-32. (2009)

11. R.F. Gabbasov, A.R. Gabbasov, V.V. Filatov, Numerical construction of discontinuous solutions to the problems of structural mechanics. Moscow: Publisher ASV, $280 \mathrm{p}$. (2008)

12. V. Shuller, Construction of tall buildings, Moscow, Stroyizdat Publ., 248 p. (1979)

13. V.V. Filatov, Calculation of through trusses using theory of composite rods A.R. Rzhanitsyna, Bulletin of MGSU, 9, pp. 23-31. (2013) 